\title{
A CLASS OF CONTINUED FRACTION INEQUALITIES
}

\author{
SAED SAMADI AND AKINORI NISHIHARA
}

Abstract. Given a finite sequence of positive real numbers, we construct terminating continued fractions whose partial denominators are formed by the arrangement of the numbers according to simple rules. This does not impose any restriction on the generality of our results and all simple continued fractions can be recast and formed according to these rules. After showing that the resulting finite continued fractions are multivariate convex or concave functions of the given sequence, we derive a class of inequalities using results from the theory of majorization. The main result of this paper is expressed in the form of inequalities connecting certain types of finite continued fractions and Fibonacci numbers.

Mathematics subject classification (2010): 26D07, 26A51, 11A55.

Keywords and phrases: Inequalities, continued fractions, convex functions, concave functions, majorization, Fibonacci sequence.

\section{REFERENCES}

[1] C. BRezins KI, History of Continued Fractions and Padé Approximants, Springer, 1991.

[2] A. Ya. Khinchin, Continued Fractions, Translated from the 3rd Russian edition of 1961, The University of Chicago Press, 1964.

[3] W. B. Jones And W. J. Thron, Continued Fractions. Analytic Theory and Applications, Encyclopedia of Mathematics and its Applications, Addison Wesley, 1980.

[4] L. Lorentzen and H. WaAdeland, Continued Fractions with Applications, NorthHolland, Amsterdam, 1992.

[5] J. Tong, Some Inequalities for Diophantine Approximation by Continued Fractions, Bulletin of the Australian Mathematical Society, 41 (1990), 249-253.

[6] R. M. Dudley, Some Inequalities for Continued Fractions, Mathematics of computation, 49 (1987) $585-593$.

[7] C. Berge, Topological spaces, Oliver and Boyd, London, 1963.

[8] A. W. Marshall, I. Olkin, And B. C. Arnold, Inequalities: Theory of Majorization and its Applications, Springer Science+Business Media, 2010. 